ISSN: 2277-3754

ISO 9001:2008 Certified

International Journal of Engineering and Innovative Technology (IJEIT)

Volume 10, Issue 2, August 2020

\title{
Impact of road geometric design elements on road traffic accidents in the city of Yaounde Cameroon
}

MBESSA Michel ${ }^{1 *}$ WOUNBA Jean Francois ${ }^{2 * *}$ NKENG George ELAMBO ${ }^{3 * * *}$ WANE TAMO Gilles Delore ${ }^{4 * * * *}$

1- Head of the Department of Civil Engineering, National Advanced School of Public Works Yaounde, Ministry of Public

Works, P.O. Box 510, Yaounde, Cameroon

2- Department of Town Planning, National Advanced School of Public Works Yaounde, Ministry of Public Works, P.O. Box

510, Yaounde, Cameroon

3- Director of the National Advanced School of Public Works Yaounde, Ministry of Public Works, P.O. Box 510, Yaounde,

Cameroon

4- Department of Civil Engineering, National Advanced School of Public Works Yaounde, Ministry of Public Works, P.O.

Box 510, Yaounde, Cameroon

\begin{abstract}
The objective of this research was to investigate the effect of road geometric design elements on road traffic accident occurrence in Yaounde. Collection of data relevant for this study was performed in two phases, beginning with the accident data collection and later the geometric and environment data collection. A total of 483 accident reports recorded from October 2018 to October 2019 were collected at the General Delegation for National Security (GDNS). These served two main purposes which were the determination of general accident characteristics and the identification of accident-prone locations (black spots) in Yaounde. On account of previous works, two main criteria (accident frequency and injury severity density) were then used for the identification of 11 road segments and 4 intersections as accident-prone locations. These accident-prone locations obtained were digitalized using Arch-GIS 10.3 tool to obtain an accident-prone location map. An investigation of the identified accident-prone locations was then performed using prepared forms to determine which roadway elements have a great influence on the occurrence of accidents. Results indicate that the reduction of road surface width, absence of sidewalk, absence of median markings, poor road geometric alignment, lack of access control, lack of appropriate parking space, absence of crosswalk, lack of channelization at intersections, presence of street vendors and waste accumulation have a significant impact on crash occurrence. This led to the proposal of solutions such as the design of paved sidewalks of adequate width and the provision of marked crosswalks for pedestrian safety, the provision of median markings to separate opposite streams of traffic, the design of appropriate channelization at intersections, provision of appropriate parking zones etc. to improve road safety.
\end{abstract}

Keywords: road safety, road traffic accident, accident-prone locations, road geometric elements.

\section{INTRODUCTION}

Road transport is a critical mode of transportation in a country's development as it improves standards of living as well as it contributes to economic growth. However, with the fast-growing population and competition to provide more luxurious traveling services, the road infrastructure has grown bigger and is more difficult to manage.

Manuscript received: 21 July 2020

Manuscript received in revised form: 17 August 2020

Manuscript accepted: 02 September 2020

Manuscript Available online: 15 September 2020
As a result, we experience an exponential rise in the number of road traffic accidents worldwide which has led to road crash becoming the $9^{\text {th }}$ leading cause of death for all ages in 2014 and is projected to rise to $5^{\text {th }}$ place if nothing is done (WHO, 2010), thus regarded as a major economic, social and health issue. WHO (2018) articulates that each year an estimated 1.3 million people around the world are killed and about 20 to 50 million are injured as a result of road traffic accidents. This causes not only grief and suffering but also economic losses to families and nations as it costs on average 3\% of countries' gross national product. WHO recent reports show that African countries are one of the most touched with $23 \%$ of the victims even though they possess only $2 \%$ of the world car fleet.

With respect to official national reports, Cameroon records an average of 16,583 road accidents yearly, killing more than 1,000 people. According to WHO reports, a total of 1,879 deaths due to traffic accidents were recorded in Cameroon for the year 2016. Yaounde, capital of Cameroon and second most populated city after Douala is highly affected by the increasing mortality rate due to road crashes. Driver behavior, road geometry, traffic volume and vehicle state are among the numerous factors responsible for these road traffic accidents. These factors can be categorized into three main groups namely human factors, vehicle factors and roadway/environment factors. Among these groups, roadway/environment factors are the scope of civil engineering professionals, thus it is within this framework relating to road safety in urban areas that the failure in considering road safety in the geometric design of roads in Yaounde is raised as a problem. That's why the question of how the geometric design of the Yaounde road network can be ameliorated to reduce crashes is asked.

The overall objective of this work is therefore to identify road geometric design and environment elements that contribute to road traffic accident occurrence and crash severity and propose solutions to improve road safety. 


\section{ISO 9001:2008 Certified}

\section{International Journal of Engineering and Innovative Technology (IJEIT)}

Volume 10, Issue 2, August 2020

\section{METHODOLOGY}

The methodology adopted consisted mainly of recognition of the study area, collection of data (road traffic accident data and road geometric data) and analysis of the collected data.

\section{- Study area}

This research was performed in Yaounde which is the political capital of Cameroon and headquarter of the Centre Region. Yaounde has a relief dominated by hills and valleys with altitude ranging from $586 \mathrm{~m}$ to $1277 \mathrm{~m}$, where reigns a tropical wet and dry climate with annual average temperature of $23.7^{\circ} \mathrm{C}$. The average precipitation is $1650 \mathrm{~mm}$ of rain per year and average humidity is $80 \%$. The city has a population of at least 2,800,000 inhabitants and economic activities based on all sectors. The city's road network consists of three main types of roads namely primary roads, secondary roads and tertiary roads. Primary roads which serve as national roads for vehicles crossing the city are generally 2 lanes paved roads with a painted central median and a few 4 lanes roads with raised central median. Secondary roads are mainly 2 lanes paved roads which link primary roads and the urban center to different quarters and peripheries while tertiary roads provide access into the quarters of Yaounde. These access roads are either 1 lane or 2 lanes with no median, often unpaved, very dusty and easily accessible by motorbikes.

\section{- Data collection}

Two main types of data were necessary for this study namely road traffic accident data and road geometric data.

\section{- $\quad$ Road traffic accident data}

All registered accident reports for a period going from October 2018 to October 2019 were collected from the General Delegation of National Security (GDNS). These reports included general information on accidents such as the day of the week, the time of the day, crash severity, accident location, road type, type of collision, illumination, weather conditions, driver's faults, car defaults, infrastructure defaults, vehicle service years, vehicle type, vehicle activity, vehicle ownership, insurance validity, driver's age, gender, socio-professional category, driving license, use of safety devices (seat belt, helmet) and other necessary information. The reports were gathered and transferred into Excel sheets in order to determine the general characteristics of accidents and identify accident-prone locations in Yaounde.

\section{- $\quad$ Road geometric data}

The road geometric data obtained from accident-prone sites investigations was comprised of cross-sectional elements (surface width, number of lanes, sidewalk width, and median type), road alignment (number of horizontal curves and vertical grades), intersection geometry and the road environment parameters. This study focused on road segments and intersection parameters presumed to have a direct or indirect influence on the occurrence of road traffic accidents. These data were gotten through actual measurements and visual inspections using prepared forms.

\section{- Data analysis method}

\section{Road traffic accident data analysis method}

The raw accident data collected on excel sheets was organized and grouped for easy analysis. This was used to explain the general characteristics of road traffic accidents in Yaounde and obtain accident-prone locations.

Prior to the identification of accident-prone locations, the road network was divided into segments and intersections with respect to the homogenous segment approach to ensure homogeneity of parameters and sites with less than 2 accidents were considered insignificant. According to AASHTO (2010) the homogeneous highway segment approach consists of dividing the highway into segments separated by major intersections, a change in horizontal alignment and geometric elements or a major change of land use. Hence the road segment length varied from approximately $100 \mathrm{~m}$ to $1000 \mathrm{~m}$.

Two criteria were then considered for the identification namely accident frequency and injury severity density (ISD). Accident frequencies gotten with Eq. (1) were used to eliminate false hazardous locations. With respect to a similar study carried out in Canada by Soto Rodriguez (2014), the accident frequency of each site was compared to threshold frequencies of 4 accidents for intersections and 8 accidents per $\mathrm{km}$ for road segments. Sites with frequencies greater than the threshold value were considered potentially problematic and tested using the second criteria.

The ISD represents the average accident severity and is obtained by weighting accidents differently according to their severity (Elvik, 2007). With severity levels being property damage only (PDO), Light (slight) injury, serious injury and fatal accident, the more serious the accidents, the higher their weight. ISD was evaluated using Eq. (2) with weightage points obtained by modifying those used in Malaysia (Rahim, Marjan, \& Voon, 2013) which is valid for developing countries, due to the lack of distinction between severe and light injury accidents in the accident reports. The accident-prone locations were then obtained by comparing the ISD values of each potentially problematic site with a threshold value presented by Eq. (3) as proposed by Zekios (2015).

The identified accident-prone locations were then listed and subjected to mapping using ArcGIS. The mapping was simply done by highlighting the hazardous segments and intersections on the Yaounde road network map to obtain the accident-prone locations map.

\section{- $\quad$ Road geometric data analysis approach}

Once the accident-prone locations were identified and geometric data obtained, the factors investigated in the geometric design of these road sections were organized and presented in summarized tabular format for making further analysis. A descriptive analysis of the geometric and environment data was done with the aim of understanding the influence road geometric and environment parameters can have on accident occurrence in Yaounde. 


\section{ISO 9001:2008 Certified}

International Journal of Engineering and Innovative Technology (IJEIT)

Volume 10, Issue 2, August 2020

\section{RESULTS AND DISCUSSIONS}

\section{- $\quad$ General characteristics of road traffic accidents}

From October 2018 to October 2019, 483 accidents were officially registered in the city of Yaounde. Among these accidents, 289 resulted to property damage only, 149 resulted to both light and serious injuries and 45 were fatal accidents which resulted to one or more deaths. A total of 812 vehicles were involved in these crashes with at least 1073 identified victims. Here are some variations of road traffic accidents by type of victims, time of the day, vehicle type, collision type and light condition.

\section{- Victims of road traffic accidents}

Amongst the 1073 victims identified, $76 \%$ were drivers, $11 \%$ were passengers, $8 \%$ were pedestrians and $5 \%$ were not specified (Figure 1). The very high percentage of drivers is mainly due to the fact that they are the most exposed to this hazard and also because in many accident cases, passengers or pedestrians involved leave the accident scene before the arrival of police, thus are not registered in the accident report.

\section{- $\quad$ Accident variation by time of the day}

Road traffic accidents vary with time depending on road users' activities, their condition, working schedules and many other factors. As shown on Figure 2, streets were relatively safe at time intervals 10PM-6AM and 6AM-10AM with just $14 \%$ of accidents each, compared to $39 \%$ and $33 \%$ for the time intervals 10AM-4PM and 4PM-10PM respectively. However, the intervals 4PM-10PM and 10PM-6AM have the highest number of fatal accidents with 15 and 14 accidents respectively as this englobes dawn, night and dusk, when streets are dark, and visibility reduced.

\section{- $\quad$ Accident variation by vehicle type}

As shown in Table 1, automobiles represent $55 \%$ of the total number of cars involved in road accidents during the study period. Motorbikes and heavy trucks share the second place with $6.5 \%$ each. $4 \mathrm{X} 4$ automobiles, utility vehicles, light trucks and articulated trucks all fall within the range 4 to $6 \%$. Bicycles occupy the last spot with just $0.5 \%$, mainly because very few people use bicycles as Yaounde road network is not adapted for bicycle movement. $5.5 \%$ of the vehicles were not properly identified.

Table 1. Accident variation by vehicle type

\begin{tabular}{|l|l|l|}
\hline VEHICLE TYPE & TOTAL & PERCENTAGE \\
\hline BICYCLE & 4 & $0.5 \%$ \\
\hline MOTORBIKE & 53 & $6.5 \%$ \\
\hline TRICYCLE & 17 & $2.1 \%$ \\
\hline AUTOMOBILE & 447 & $55.0 \%$ \\
\hline AUTO 4X4 & 34 & $4.2 \%$ \\
\hline UTILITY VEHICLE & 44 & $5.4 \%$ \\
\hline LIGHT TRUCK & 47 & $5.8 \%$ \\
\hline HEAVY TRUCK & 53 & $6.5 \%$ \\
\hline MINIBUS & 18 & $2.2 \%$ \\
\hline BUS & 10 & $1.2 \%$ \\
\hline
\end{tabular}

\begin{tabular}{|l|l|l|}
\hline ARTICULATED & & \\
TRUCK & 33 & $4.1 \%$ \\
OTHER & 9 & $1.1 \%$ \\
UNKNOWN & 43 & $5.3 \%$ \\
SUM & 812 & $100.0 \%$ \\
\hline
\end{tabular}

\section{- $\quad$ Accident variation by collision type}

A variation was noticed on the percentage of road crashes and severity according to the type of collision. As presented on Figure 3, the highest percentage of road accidents was recorded for rear end collisions (28\%), with side swipe crashes coming second (25\%) and head on collisions third (14\%). On the other hand, vehicle to pedestrian collision was far ahead in terms of fatal accidents with 19 crashes (more than $42 \%$ of the total fatal accidents), indicating that pedestrians' lives are the most at risk in case of an accident.

\section{- $\quad$ Accident variation by light condition}

Figure 4 summarizes crash occurrence by different light conditions during the study period. This shows that $64.8 \%$ accidents occurred during daylight and $14.2 \%$ of accidents occurred at night with dark roads (no public lighting + public lighting off), which is about 3 times greater than the $5.6 \%$ of accidents which occurred at night with public lighting on.

\section{- Identification of accident-prone locations}

With respect to the homogenous segment approach and the basic criteria of at least 2 accidents per site set, 34 road segment and 15 intersections were preselected as accident locations in the city of Yaounde and their frequencies calculated. From these preselected accident locations, 20 road segments were found to have frequencies greater than the threshold frequency of 8 for road segments, and 7 intersections were found to have frequencies greater than the threshold value of 4 for intersections. The ISD's of these potential accident-prone locations were then gotten using Equation (2) and the corresponding ISD threshold values for both road segments and intersections gotten with Equation (3) were 20 and 2 respectively. After comparing the different ISD's with the calculated threshold values, the lists of the identified accident-prone locations are presented in Tables 2 and 3. The accident-prone location map (Error! Reference source not found.) was then obtained using ArcGIS.

Table 2. Identified accident-prone segments

\begin{tabular}{|c|c|c|c|c|c|}
\hline $\begin{array}{l}\mathbf{N} \\
\mathbf{0}\end{array}$ & Code & Road Segment & $\begin{array}{c}\text { Length } \\
(\mathbf{m})\end{array}$ & Frequency & ISD \\
\hline 1 & $\mathrm{~T} 1$ & $\begin{array}{l}\text { Descent stepmother } \\
\text {-Anguissa }\end{array}$ & 92 & 22 & 22 \\
\hline 2 & $\mathrm{~T} 2$ & Climb Zoe & 86 & 23 & 23 \\
\hline 3 & $\mathrm{~T} 3$ & Meka Laboratory & 392 & 15 & 20 \\
\hline 4 & $\mathrm{~T} 5$ & Rue Over there & 275 & 15 & 29 \\
\hline 5 & T6 & Eight Market & 120 & 25 & 25 \\
\hline
\end{tabular}


ISSN: 2277-3754

ISO 9001:2008 Certified

International Journal of Engineering and Innovative Technology (IJEIT)

Volume 10, Issue 2, August 2020

\begin{tabular}{|l|l|l|l|l|l|}
\hline 6 & T9 & Crossroads & 452 & 9 & 20 \\
\hline
\end{tabular}

Table 3. Identified accident-prone intersections

\begin{tabular}{|c|c|l|c|c|}
\hline No & Code & \multicolumn{1}{|c|}{ Intersection } & Frequency & ISD \\
\hline 1 & C2 & Rond Point Express & 4 & 2.25 \\
\hline 2 & C9 & $\begin{array}{l}\text { Carrefour Texaco } \\
\text { Omnisport }\end{array}$ & 5 & 2 \\
\hline 4 & C11 & $\begin{array}{l}\text { Deuxième } \\
\text { échangeur Ahala }\end{array}$ & $\begin{array}{l}\text { Carrefour de } \\
\text { l'Amitié }\end{array}$ & 3.4 \\
\hline
\end{tabular}

- Investigation of accident-prone locations

This consisted in collecting road geometric and environment data from accident-prone locations using prepared forms, then doing a descriptive analysis of the collected roadway data in order to know the effects of

existing road geometric design elements on the occurrence of road traffic accidents.

\section{- Collected road geometric design data}

Some of the primary road geometric design elements susceptible of influencing road safety at the accident-prone road intersections and along road segments, investigated in this study are presented in Tables 4 and 5 respectively.

Table 4. Geometric data of accident-prone intersections

\begin{tabular}{|c|c|c|c|c|c|}
\hline \multirow[b]{2}{*}{ No } & \multirow{2}{*}{$\begin{array}{c}\text { Road } \\
\text { geometric data }\end{array}$} & \multicolumn{4}{|c|}{ Identified accident-prone intersections } \\
\hline & & $\mathrm{C} 2$ & C9 & C11 & $\mathrm{C12}$ \\
\hline 1 & $\begin{array}{l}\text { Intersection } \\
\text { type }\end{array}$ & Four-leg & Four-leg & $\begin{array}{c}\text { Three-1 } \\
\text { eg }\end{array}$ & Four-leg \\
\hline 2 & $\begin{array}{l}\text { Intersection } \\
\text { control }\end{array}$ & Gyratory & Gyratory & Priority & Gyratory \\
\hline 3 & $\begin{array}{l}\text { Central island } \\
\text { type }\end{array}$ & Raised & Raised & None & Raised \\
\hline 4 & Channelization & Partly & None & None & None \\
\hline 5 & Crosswalk & No & No & No & No \\
\hline 6 & Street vendors & Yes & Yes & Yes & Yes \\
\hline 7 & $\begin{array}{l}\text { Waste } \\
\text { accumulation }\end{array}$ & No & No & No & No \\
\hline
\end{tabular}

Table 5. Geometric data of accident-prone segments

\begin{tabular}{|c|c|c|c|c|c|c|c|c|c|c|c|c|c|}
\hline & & & & & & & & & & & & & \\
\hline & & & & & & & entific & Accid & t-Prone & Segmen & & & \\
\hline & oad Geometri & c Data & T1 & $\mathbf{T} 2$ & T3 & T5 & T6 & T9 & T10 & T12 & T15 & T19 & T27 \\
\hline 1 & Surface width & & 7.2 & 7.2 & 7.5 & 14 & 7 & 7.3 & 10 & 7.5 & 7 & 7.2 & 7.5 \\
\hline$?$ & Sidewalk & Left & 0 & 0 & 1.7 & 1 & 0 & 0 & 2.5 & 0 & 0 & 2 & 0 \\
\hline & & Right & 0 & 0 & 1.5 & 1 & 0 & 0 & 0 & 0 & 0 & 2 & 0 \\
\hline 3 & Median type & & $\begin{array}{c}\text { No } \\
\mathrm{e}\end{array}$ & None & $\begin{array}{c}\text { Painte } \\
\text { d }\end{array}$ & $\begin{array}{c}\text { Raise } \\
\text { d }\end{array}$ & $\begin{array}{c}\text { Non } \\
\mathrm{e}\end{array}$ & $\begin{array}{c}\text { Non } \\
\mathrm{e}\end{array}$ & $\begin{array}{c}\text { Painte } \\
\mathrm{d}\end{array}$ & None & $\begin{array}{c}\text { Non } \\
\mathrm{e}\end{array}$ & Painted & $\begin{array}{c}\text { Non } \\
\mathrm{e}\end{array}$ \\
\hline 4 & Median width & & 0 & 0 & 0.12 & 0.45 & 0 & 0 & 0.12 & 0 & 0 & 0.12 & 0 \\
\hline 5 & Median heigh & & 0 & 0 & 0 & 0.1 & 0 & 0 & 0 & 0 & 0 & 0 & 0 \\
\hline 6 & No of lanes & & 2 & 2 & 2 & 4 & 2 & 2 & 2 & 2 & 2 & 2 & 2 \\
\hline 7 & $\begin{array}{l}\text { No of horizon } \\
\text { curves }\end{array}$ & & 1 & 2 & 1 & 0 & 0 & 1 & 0 & 3 & 2 & 2 & 4 \\
\hline 8 & No of vertical & grades & 1 & 1 & 1 & 2 & 1 & 1 & 1 & 1 & 1 & 1 & 1 \\
\hline 9 & No of access & ooints & 2 & 3 & 5 & 5 & 2 & 3 & 3 & 10 & 3 & 5 & 4 \\
\hline 10 & No of access & controls & 0 & 0 & 2 & 1 & 0 & 1 & 1 & 1 & 0 & 1 & 0 \\
\hline 11 & Parking availe & bility & No & No & Yes & No & No & No & Yes & No & No & Yes & No \\
\hline 12 & Crosswalk & & $\mathrm{No}$ & No & No & No & No & No & No & No & No & No & No \\
\hline 13 & Street vendor & & $\mathrm{Ye}$ & No & Yes & Yes & Yes & Yes & Yes & Yes & Yes & Yes & Yes \\
\hline 14 & Waste accum & lation & $\mathrm{Ye}$ & No & No & No & Yes & No & No & Yes & No & Yes & No \\
\hline
\end{tabular}


ISO 9001:2008 Certified

International Journal of Engineering and Innovative Technology (IJEIT)

Volume 10, Issue 2, August 2020

-

\section{Effects of existing road geometric design elements on the occurrence of accidents}

Surface width

From the eleven accident-prone segments investigated, nine were found to have surface widths between $7 \mathrm{~m}$ and $7.5 \mathrm{~m}$ with average lane width of $3.6 \mathrm{~m}$. Traditionally, wider lanes are associated with increased safety but from previous studies like that of Zegeer, Deen, \& Mayes (1981), the optimal lane width for urban road safety has been agreed to lie between $3.4 \mathrm{~m}$ to $3.7 \mathrm{~m}$. This is because when the average travel lane width is wider than $3.5 \mathrm{~m}$, the positive safety effect is offset by higher operational speeds and unsafe maneuvers such as over taking despite oncoming traffic. However, a reduction of the surface width below optimal width as observed along most road segments due to loss of pavement and/or inappropriate parking has a negative safety effect. This is because the available lane width is insufficient to accommodate large vehicles like $4 \times 4$ automobiles, trucks, and buses, hence increase the risk of head-on and side swipe collisions between opposite moving vehicles.

\section{- Sidewalk}

For pedestrian safety in urban areas, AASHTO guide recommends the design of paved and continuous sidewalks on both sides of roadways with minimum width of $1.5 \mathrm{~m}$. Out of the eleven segments investigated, only two respect this norm. One has sidewalks on both sides but not of required width, one has the required sidewalk width on one side and seven don't have sidewalks at all. In most cases where sidewalks are present, they are occupied by street vendors and parked cars. As a result, pedestrians are obliged to move on the road surface and this mixture of road users and motorized traffic leads to a considerably larger set of potential crash risk opportunities for pedestrians. In general, the absence of appropriate sidewalks in the design of Yaounde streets and lack of maintenance of existing ones is a major road safety issue.

\section{- Median type}

From the data collected, out of the eleven accident-prone road segments, the only 4 lane road segment has a raised median, three of the ten 2 lane road segments have painted medians and seven do not have medians. The absence of median has the effect of increasing the risk for specific types of accidents such as head-on and side swipe collisions which together account for about $39 \%$ of crashes in Yaounde. Painted medians allow vehicles maneuvers at any locations of the road segments thus offer less safety with respect to raised medians which partially (or fully) control vehicles' movements from one direction to the other. However, raised medians are more appropriate for 4 lane roads as they increase traffic speed by reducing the perceived friction of opposite traffic flow and occupy space that can be used for sidewalks or on-street parking. Hence, the use of raised medians on 4 lane roads is not a threat to road safety but the absence of medians on 2 lane roads can be regarded as one of the most contributing factors to road insecurity in Yaounde.

\section{- Number of lanes}

Ten road segments out of the eleven investigated are 2 lane roads. Almost all studies do conclude that the higher the number of lanes, the higher the crash rate on urban roadways. This can be explained by the higher speeds and frequent change of lanes by drivers, increasing the probability of occurrence of road traffic accident. The number of lanes cannot therefore be regarded as an influential factor to traffic safety in Yaounde.

\section{- Road alignment}

Crash rates are higher on sections with curves or grades and highest on roads having combinations of curves and grades than on level tangent roadway sections. From the eleven road segments controlled, eight segments have combinations of horizontal curves and vertical grades which cause safety problems to inattentive drivers and those practicing high-speed. This tends to increase the potential of head on and rear end collisions, so poor road alignment is a significant parameter influencing road safety in Yaounde.

\section{- Access points and access control}

Road segments associated with a high number of access points are exposed to unexpected traffics that collide with high-speed oncoming vehicles, hence the need for access controls to create less opportunity for conflicts and thus reduce the risk of accident occurrence. 45 access points in total were identified along the eleven road segments studied and only 7 of these points access have controls. This means $84 \%$ of the access points are uncontrolled (conflict points), thus susceptible of generating rear end and side swipe crashes which account to over $50 \%$ of the total crash types in Yaounde. Consequently, uncontrolled access points are a major influence of road traffic accident occurrence in Yaounde.

\section{- $\quad$ Parking availability}

Only three road segments out of eleven have appropriate car parking facilities provided by either public services or private institutions. The other road segments either don't have parking space at all or part of the road surface and sidewalks are transformed to parking which is inappropriate. The main consequences are that the total road surface available for circulation is reduced and pedestrians are forced to move on the road surface beside moving cars. The numerous poorly parked cars along these road segments create several conflict points and therefore have a great impact on road traffic accidents.

\section{- Crosswalk}

Crosswalks should be marked at all intersections and along road segments where there exist conflict between pedestrian and vehicle movements and other appropriate points of pedestrian concentration. Marked pedestrian crosswalks are completely absent along all road segments and at all intersections investigated. The absence of crosswalks and the lack of appropriate sidewalks are important factors influencing vehicle-to-pedestrian type of collisions which contribute to $11 \%$ of the total crashes and $42 \%$ of the total fatal accidents in Yaounde. Thus, the 


\section{ISO 9001:2008 Certified}

\section{International Journal of Engineering and Innovative Technology (IJEIT)}

Volume 10, Issue 2, August 2020

absence of crosswalks greatly influences pedestrian safety in the city.

\section{- $\quad$ Street vendors and waste accumulation}

Among the fifteen accident-prone locations (road segments and intersections) investigated, a total of fourteen had street vendors and four had waste accumulation. These street vendors and wastes occupy the road surface and roadsides, thereby reducing the available road surface width, acting as visual clutter to oncoming vehicles and obliging pedestrians to walk on the road surface. The presence of street vendors and waste accumulation along these road segments and at intersections create danger zones with high risk of traffic accidents.

\section{- Intersection type and control}

The number of conflict points at an intersection increases exponentially with the number of legs $(6$ vehicle-vehicle conflict points for three-legged, 24 for four-legged and 60 for five-legged intersections), meaning accidents will be more prone at four-legged intersections than at three-legged intersections. The most effective way of reducing crashes and crash severity at intersections is using gyrators or mini roundabouts as they help reduce the vehicular approach speeds, the potential for wrong way driving and the number of conflict points. Given that three out of the four intersections identified as accident-prone are four-legged intersections with gyratory control, this cannot be looked as a main safety parameter affecting road safety in Yaounde.

\section{- Central island}

Three of the identified accident-prone intersections have a raised central island while one does not have a central island. Normally, the number of traffic accidents is greatly reduced at intersections with central island compared to intersections without. Raised central islands offer more specific guidance to drivers, thus more safety. Hence, road insecurity at these identified accident-prone intersections is influenced by other geometric parameters other than the presence of a central island.

\section{- Channelization}

None of the four intersections controlled have adequate channelization. Three are unchannelized and one is partly channelized. Without channelization of movement, a driver traversing the intersection is confronted by a large surface area without any positive guidance on the route to be followed and the unpredictable selection of travelled path represents a distinct hazard to other vehicles in the intersection area. The absence of channelization makes road users vulnerable to road crashes at intersections and is therefore a major road safety issue in the city of Yaounde.

\section{- $\quad$ Solutions to improve safety}

With respect to the general condition of road segments and intersections in Yaounde, safety of pedestrians, vehicles and their occupants can be guaranteed to an extent with the following series of improvements
- The design of paved sidewalks on both sides of roadways with adequate width, continuous, travel free and well maintained to guarantee pedestrian safety.

- Median markings should be provided through the entire length of roadways while road dividers can be implemented along the most dangerous road segments with frequent head-on collisions.

- Avoid sharp curves and steep grades and minimize the combination of both in the design of new roads and reconstruction of old ones.

- Manage and control access points by means of driveway regulations, traffic signals and geometric design features such as raised curbed medians and appropriate median openings to improve traffic performance and safety.

- Appropriate off-street parking areas should be designed in zones with high commercial activities.

- On-street parking should be prohibited along road segments with average surface width of $7.2 \mathrm{~m}$ and where necessary, provided on curb lanes of at least $3 \mathrm{~m}$ wide, with signs and road markings indicating motorists where to park.

- Restrict parking services at road segments with several access road facilities.

- Street crossing locations should be reviewed and provided with marked crosswalks plus additional safety treatments like countdown signals.

- Provide safety refuge islands along road segments with raised medians in order to shorten crossing distance and improve pedestrian safety.

- Speed calming devices should be placed near schools, hospitals, recreational and residential areas and before crosswalks to reduce over speeding.

- The implementation of roundabout (gyratory control type of intersection) at intersections with heavy traffic is the best design option as it is safer, more efficient, less costly and more aesthetically appealing than conventional intersection design.

- Appropriate channelization (splitter islands) should be placed at all intersections such that proper course of travel is immediately obvious, easy to follow and continuous.

- Ensure adequate lighting at night by installing traffic lights and repairing existing ones especially at crossing locations.

- Provide special lanes for motorbikes and/or bicycles and traffic separators in order to separate the different types of traffic.

- Provide well designed selling points to relocate street vendors who illegally occupy the sidewalks, roadsides and part of the road surface in some cases. 


\section{ISSN: 2277-3754 \\ ISO 9001:2008 Certified \\ International Journal of Engineering and Innovative Technology (IJEIT) \\ Volume 10, Issue 2, August 2020}

- Avoid the accumulation of waste on the road surface and roadsides by promoting regular and effective cleaning campaigns.

\section{CONCLUSION}

The main objective of this study was to identify road geometric design elements that contribute to crash occurrence and crash severity in Yaounde and propose appropriate solutions to improve road safety. The two main types of data collected were road traffic accident data and road geometric and environment data. Based on road traffic accident records for a single year (from October 2018 to October 2019), 11 road segments and 4 intersections were identified as accident-prone locations. Investigation of the effect of relevant road geometric and environment elements on road safety at these locations showed that parameters having a great impact on road safety in Yaounde are the reduction of surface width, absence of sidewalk, absence of median markings, poor road geometric alignment, lack of access control, lack of appropriate parking space, absence of crosswalk, lack of channelization at intersections, presence of street vendors and waste accumulation. This led to the proposal of solutions such as the design of paved sidewalks of adequate width and the provision of marked crosswalks for pedestrian safety, the provision of median markings to separate opposite streams of traffic, the design of appropriate channelization at intersections, provision of appropriate parking zones, management and control of access points and many others. Since road crashes generally occur due to a combination of two or more factors, it is possible to compensate for other factors with appropriate geometric design elements which optimize road safety. Hence, these findings will be helpful for future revisions of current road design standards and for the establishment of adequate policies in order to limit the influence of road geometric elements on traffic accidents and improve road safety.

Some limitations were the lack of information on traffic characteristics (traffic volume and traffic composition), lack of information on operational speeds, high level of underreporting, inaccurate accident localisation and lack of information on road geometry in the accident reports. These limited the choice of criteria for the accident data analysis, made it difficult to determine the exact accident-prone locations and identify the factors related to road geometry that contribute to accidents.

For future works, it could be interesting to consider other parameters like traffic characteristics, operational speeds, and sight distances, horizontal degree of curvature, vertical grade steepness, set back distances and land uses. Also, a more detailed evaluation of road safety at intersections is recommended with parameters like angle between approaching roads, perception-reaction distance, maneuver distance and queue-storage distance.

\section{REFERENCES}

[1] AASHTO, 2010. Highway Safety Manual (First edit) Washington, DC: American Association of State Highway and Transportation Officials.

[2] Rodriguez, J.F.S. ," Analysis of Accidents on the Municipal Road Network and Identification of Problematic Sites" Polytechnic university of Montreal, Vol. 8,2014.pp. 16-18.

[3] Rune Elvik," State-of-the-art approaches to road accident black spot management and safety analysis of road", Institute of Transport Economics Norwegian Centre for Transport Research, 2007.

[4] Rahim, S. A. S., Marjan, J. M., \& Voon, W. S.,"Guideline on Accident-Prone Area Identification for Automated Enforcement System (AES), Malaysian Institute of Road Safety Research (MIROS), 2013.

[5] Zegeer, Charles V, Deen, Robert C, Mayes, Jesse G,"EFFECT OF LANE AND SHOULDER WIDTHS ON ACCIDENT REDUCTION ON RURAL, TWO-LANE ROADS", Transportation Research Record,1981. 